\title{
LAND COVER / LAND USE MONITORING FOR AGRICULTURE FEATURES CLASSIFICATION
}

\author{
Sona H. Guliyeva \\ National Aviation Academy, Aerospace Faculty, Aerospace Monitoring of Environment Department, \\ AZ1045, Mardakan av. 30, Baku, Azerbaijan - guliyeva.s.h@gmail.com
}

KEY WORDS: remote sensing, crop, monitoring, agriculture, image processing, GIS, NDVI, AZERSKY

\begin{abstract}
:
Remote sensing applications are directed to agricultural observation and monitoring. It has been huge of scientific papers are dedicated to the research of the contribution of remote sensing for agriculture studies. There are several global challenges needed to be considered within agriculture activities. It can be embraced by the main agriculture sector facing the obstacles impacting the production and productivity of the sector. These are the following options that can be pointed out: biomass and yield estimation; vegetation vigor and drought stress monitoring; assessment of crop phenological development; crop acreage estimation and cropland mapping; and mapping of disturbances and Land Use/Land Cover changes. In this study has been undertaken the realization of satellite-based Land Use/Land Cover monitoring based on various optical satellite data. It has been used satellite images taken from satellites AZERSKY, RapidEye, Sentinel-2B and further processed for Land Use/Land Cover classification. Following the complex approach of the supervised and unsupervised classification, the methodology has been used for satellite image processing. As the main satellite imagery for monitoring crop condition were AZERSKY taken during the growing season, from May to June of 2019 year. The study area was some part of the Sheki region, which covers the central part of the southern slope of the Greater Caucasus Mountain Range within Azerbaijan Republic. In this research work satellite imagery processing and mapping has been carried out on the basis of software application of ArcGIS Pro 2.5.
\end{abstract}

\section{INTRODUCTION}

The development of methods for operational satellite monitoring of crops began almost immediately after data from satellite imagery of the Earth's surface became available. Historically already in 1972 , the USA carried out the LACIE project, within the framework of which the state of crops in the former Soviet Union was monitored and the yield forecast based on satellite imagery data was compiled for the first time (Erickson, 1984)

There is no doubt that the remote sensing method is widely used in agriculture. The use of remote sensing is the best instrument for monitoring of agricultural activities during all stages of production. It relates to the seasonal patterns related to the biological lifecycle of crops. The production depends secondly on the physical landscape including climatic driving variables and agricultural management practices. All variables are highly variable in space and time. Moreover, circumstances as productivity change within short periods.

Remote sensing can significantly contribute to providing a timely and accurate image of the agricultural sector, as the convenient and suitable for gathering appropriate information over large areas with high accuracy (Brisco, 2014).

The use of remote sensing methods in the agriculture sector provides arguments for the enhancement of investments for agricultural monitoring systems. It follows the strong conviction that close monitoring of agricultural production systems is necessary (Atzberger, 2013). This increase in production must be achieved while minimizing the environmental/external impacts of agriculture. Achieving the main goal is difficult, as agriculture must cope with all circumstances no matter external factors or climate change.

The main goal of this research work is to use images taken from various satellites in the optical range for developing an automated methodology for classifying crop types in the selected study area based on the machine learning methods for land cover/land use classification.

To achieve the purpose of this study, the following tasks were set: identify crop types in the study area based on ground data; study satellite data obtained during the growing season of the study area; review and implement existing classification methods; compare the classification results of different methods from various satellites; and finally create an automatized satellite images processing scheme.

\section{STUDY AREA AND DATASET}

\subsection{Study area}

The Sheki region covers the central part of the southern slope of the Greater Caucasus Mountain Range within Azerbaijan. The total area of the region is 7 thousand $\mathrm{km}^{2}$, of which agricultural land occupies more than 3 thousand $\mathrm{km}^{2}$, forests, and pastures 2 thousand $\mathrm{km}^{2}$. This region is represented by all the main types of vegetation found on the territory of the Azerbaijan Republic.

It is known, that agriculture is one of the important sources of income. Therefore, the proper management of agriculture is crucial for the region (Ustuner, 2014). The study area is located in the Sheki region of Azerbaijan and comprised of approximately $20 \mathrm{~km}^{2}$ of area (Figure 1). It covers four land use classes which are wheat, oats, barren, and water surface. 


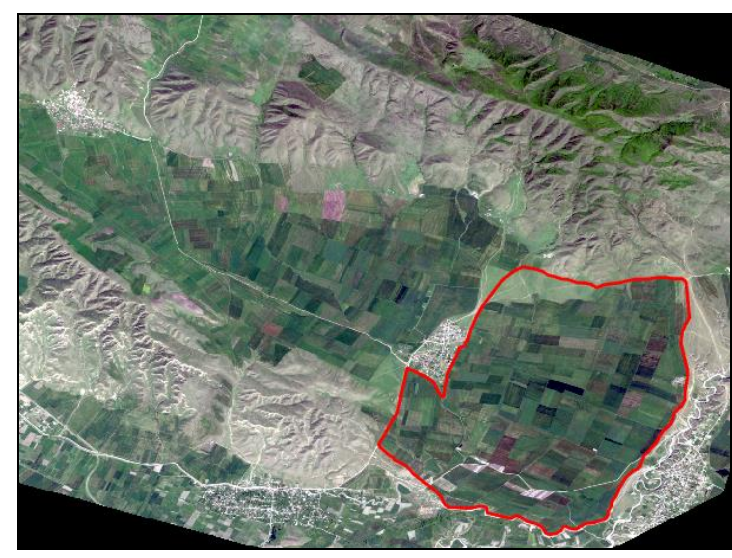

Figure 1: Study area

\subsection{Dataset}

AZERSKY, RapidEye, and Sentinel-2B satellite images were obtained from the study area using the same data collection: 23 June 2019.

AZERSKY is the first Earth Observation Satellite of Azerbaijan. Technical specifications of AZERSKY data are given as below.

\begin{tabular}{|l|l|l|c|}
\hline & Band color & $\begin{array}{l}\text { Wavelength } \\
(\mu \mathrm{m})\end{array}$ & $\begin{array}{l}\text { Spatial } \\
\text { resolution }(\mathrm{m})\end{array}$ \\
\hline MS & Blue & $0.450-0.520$ & \multirow{2}{*}{6} \\
\hline & Green & $0.530-0.590$ & \multirow{2}{*}{6} \\
\hline & Red & $0.625-0.695$ & \\
\hline & Near infrared & $0.760-0.890$ & \multirow{2}{*}{1.5} \\
\hline P & Black and white & $0.450-0.750$ & \\
\hline
\end{tabular}

Table 1. Specifications of AZERSKY data

For the assessment of vegetation development of agricultural fields, satellite images were used, obtained from the AZERSKY satellite, taken at the following dates: 02.05.2019; 15.05.2019; 22.05.2019; 03.06.2019 and 23.06.2019.

RapidEye is the first high-resolution multispectral satellite system incorporating a red-edge channel that has been commonly preferred and successfully used for agricultural and forestry applications (Ustuner, 2015). Information on spectral and spatial resolutions of RapidEye image is shown in table 2.

\begin{tabular}{|l|l|c|}
\hline $\begin{array}{l}\text { Band } \\
\text { color }\end{array}$ & $\begin{array}{l}\text { Wavelength } \\
(\mu \mathrm{m})\end{array}$ & $\begin{array}{l}\text { Spatial } \\
\text { resolution }(\mathrm{m})\end{array}$ \\
\hline Blue & $0.440-0.510$ & \multirow{2}{|c|}{5} \\
\cline { 1 - 2 } Green & $0.520-0.590$ & \multirow{2}{*}{5} \\
\cline { 1 - 1 } Red & $0.630-0.685$ & \\
\hline Red Edge & $0.690-0.730$ & \\
\hline $\begin{array}{l}\text { Near } \\
\text { infrared }\end{array}$ & $0.760-0.850$ & \\
\hline
\end{tabular}

Table 2. Specifications of RapidEye data

Sentinel-2B data provides 13 spectral bands with 10, 20, 60 meter spatial resolution. Specifications of Sentinel Data can be seen in table 3 .

\begin{tabular}{|l|c|c|}
\hline \multicolumn{1}{|c|}{ Spectral bands } & $\begin{array}{c}\text { Wavelength } \\
(\mu \mathrm{m})\end{array}$ & $\begin{array}{c}\text { Spatial } \\
\text { Resolution }(\mathrm{m})\end{array}$ \\
\hline Coastal aerosol & $0,421-0,457$ & 60 \\
\hline Blue & $0,439-0,535$ & 10 \\
\hline Green & $0,537-0,582$ & 10 \\
\hline Red & $0,646-0,685$ & 10 \\
\hline Vegetation Red Edge & $0.694-0.714$ & 20 \\
\hline Vegetation Red Edge & $0.731-0.749$ & 20 \\
\hline Vegetation Red Edge & $0.768-0.796$ & 20 \\
\hline Near infrared & $0.767-0.908$ & 10 \\
\hline Vegetation Red Edge & $0.848-0.881$ & 20 \\
\hline Water vapour & $0.931-0.958$ & 60 \\
\hline $\begin{array}{l}\text { Shortwave } \\
\text { infrared/Cirrus }\end{array}$ & $1.338-1.414$ & 60 \\
\hline Shortwave infrared 1 & $1.539-1.681$ & 20 \\
\hline Shortwave infrared 2 & $2.072-2.312$ & 20 \\
\hline
\end{tabular}

Table 3. Specifications of Sentinel-2B Data

Compared to panchromatic, multispectral images are more informative, therefore, a comprehensive analysis of the distribution of pixels in the image in the visible range of the spectrum makes it possible to determine the parameters characterizing monitoring objects or processes occurring in them (Kulik et al., 2015).

Highlighted bands in orange in the tables were used in this research, panchromatic AZERSKY satellite image was used as ancillary data for identification parcels of crop fields due to high spatial resolution.

Sentinel-2B image has been downloaded from the Open Access Hub of Copernicus. RapidEye and AZERSKY images have been provided through the Planet's "Education and Research" program and the "Promotion of Earth remote surveillance services for the sake of sustainable development of Azerbaijan" project of Azercosmos OJSCo.

Ground data on the crop types, crop yield for the 2019 year is shown in figure 2. In the meantime, for the selected fields have been provided results of soil analysis for the 2018 year.

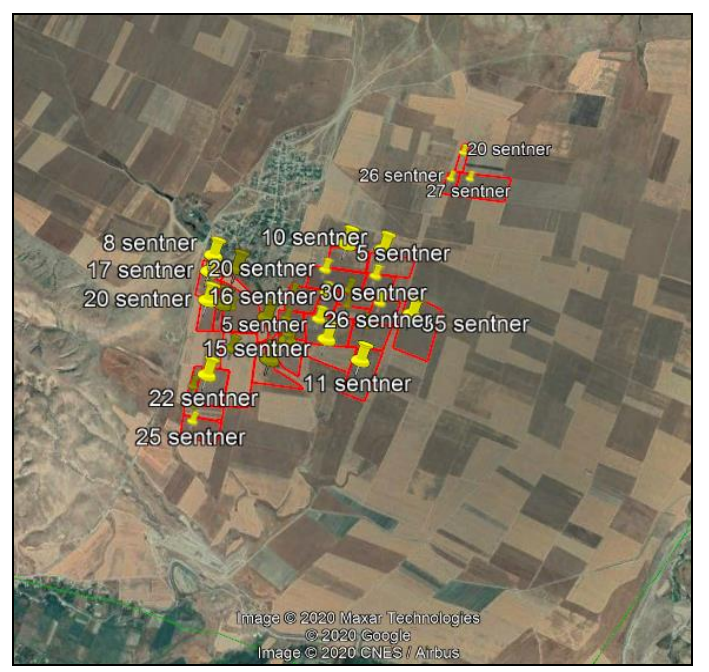

Figure 2. Ground data are shown in the Google Earth Pro 7.3

Based on this ground data training samples were created for supervised classification implementation. 


\section{METHODOLOGY}

\subsection{Pre-processing}

The basic software for Image Processing which has been used in this research was ArcGIS Pro 2.5 from ESRI.

Image pre-processing included the following steps: projecting images, removing the black background, and clipping the study area, which are shown in Figure 3, a flowchart of which was created using the ModelBuilder.

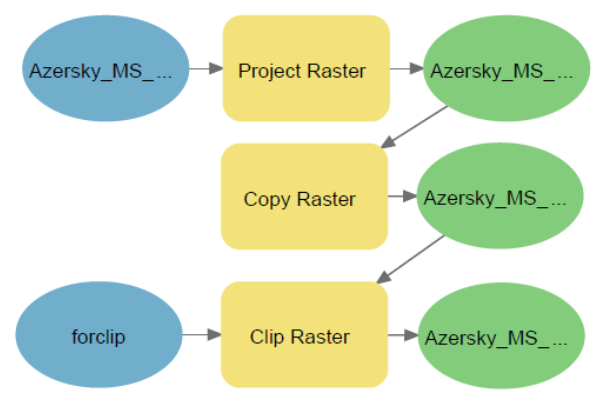

Figure 3. Pre-processing flowchart

Imagery has been projected to the UTM projection. Then copies of images were taken, and finally selected area has clipped from these images.

\subsection{Vegetation indices}

Currently, to solve most of the problems, special technologies are used to decrypt images obtained by systematic repeated shooting, which provide monitoring of the dynamics of crop development. At the same time, the NDVI (Normalized Difference Vegetation Index) index, which can be used to define the agrotechnical state of crops, was most widely used in descripting and in analyzing differences in the spectral brightness's of vegetation during the growing season (Mikhailenko, 2015). NDVI vegetation index has been actively used to monitor crops and predict yield since the early 1980s. (Tucker et a1., 1980). Differences in the response patterns of vegetation in the red and NIR ranges of the spectrum permit the calculation of NDVI (Candiago et al., 2015):

$$
N D V I=\frac{N I R-R E D}{N I R+R E D}
$$

where red and NIR for the spectral reflectance measurements acquired in the red (visible) and near-infrared regions, respectively.

Figure 4 shows the simplest workflow for implementation raster calculation by bands in ArcGIS Pro.

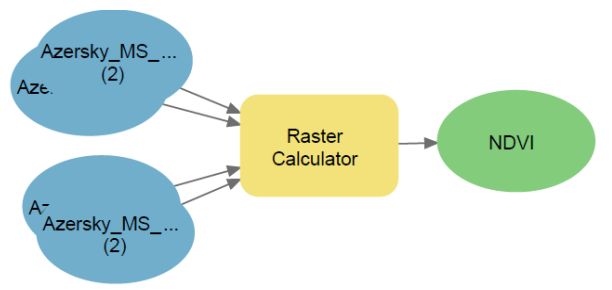

Figure 4. NDVI calculation flowchart
The NDVI vegetation index for each satellite image was calculated, and the vegetation developments of crops were estimated using satellite images for the period from May to June.

As a result of NDVI calculation for vegetation period from 02.05.2019 to 23.06.2019 taken AZERSKY satellite, index maps were created, shown in figure 5 .

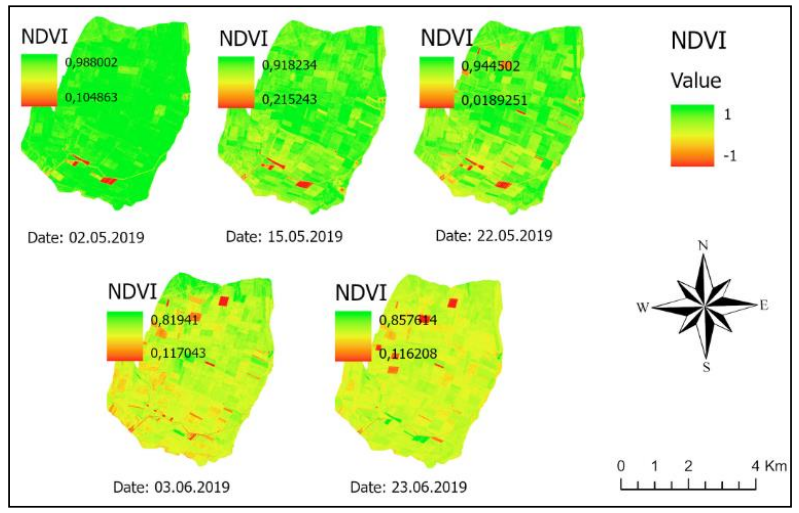

Figure 5. Classified maps by NDVI

At the beginning of the growing season, the index increases, at the time of flowering, its growth stops, then as it ripens, NDVI decreases.

Therefore, the highest value of the vegetation index was revealed at the beginning of May, which is in the intermediate from 0.104863 to 0.988002 , during the period of active plant growth.

\subsection{Classification}

Supervised and unsupervised are two primary methods of image classification.

Unsupervised classification involves the separation of image pixels into natural groupings based upon similar spectral characteristics by means of a classification algorithm and the resultant assignment of those groupings to informational classes by the analyst (Enderle, 2005).

Supervised classification involves the classification of pixels of unknown identity by means of a classification algorithm using the spectral characteristics of pixels of known informational class identified by the analyst (Campbell, 2002).

Classification methods, such as unsupervised ISO, and supervised: Maximum Likelihood Classifier (MLC), Random Trees Classifier (RTC), Support Vector Machine (SVM), were used using field and topographic data to the identification of crop types and area.

For supervised classification the following main steps were produced:

- Visual interpretation of satellite image

- Field work/define classes

- Take representative samples per class

- Analyze training samples before classification

- Select/apply appropriate classification algorithm

- Classification accuracy assessment. 
The methodology of automatized satellite image classification shown in the figure 6.

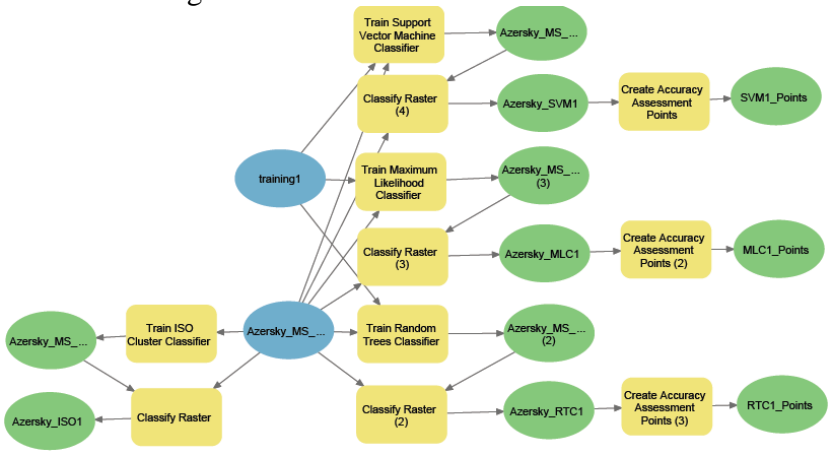

Figure 6. Flowchart of satellite images classification

Following of flowchart of automatized satellite classification next steps were implemented: unsupervised classification was performed; for supervised classification, training samples were created based on visual interpretation and the ground truth data; each image was sequentially uploaded and processed; accuracy assessment points were created, which were manually verified and based on which further accuracy assessment of classified images were performed.

In this way, 3 satellite images have been classified, which received on the same day on June 23, 2019, from various satellites: AZERSKY, RapidEye, and Sentinel-2B. Thanks to the created scheme, it became possible to speed up the image processing process.

As a result of classification implementation land cover/land use thematic maps were created.

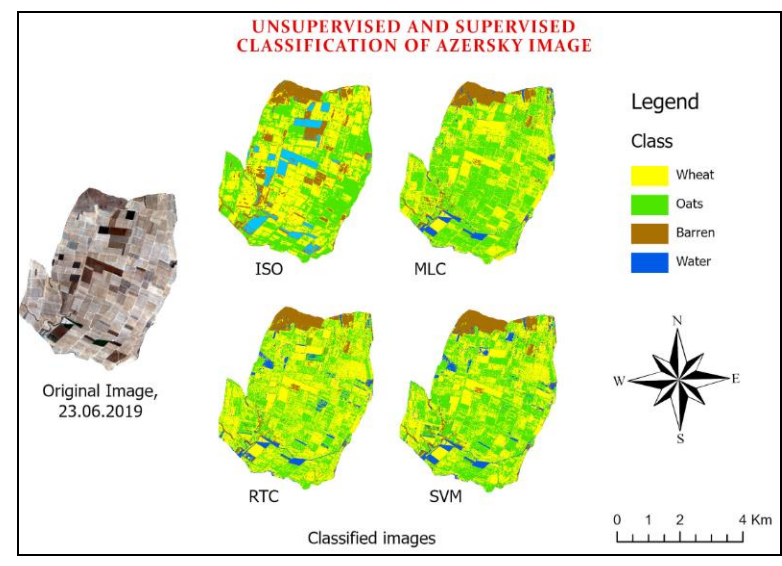

Figure 7. Classified AZERSKY images

The classification results of Iterative Self-Organizing Data Analysis Technique (ISODATA), which was used for unsupervised classification process, were interpreted visually and combined into 4 classes as created training samples for supervised classification based on the ground truth information. In the legend, the class of interests is represented by yellow, green, brown and blue colors, first wheat, second oats, third barren, and water surface, respectively.

As a result, classified images from the produced supervised classification method Support Vector Machine (SVM) classification method for different images shown in figure 8 .

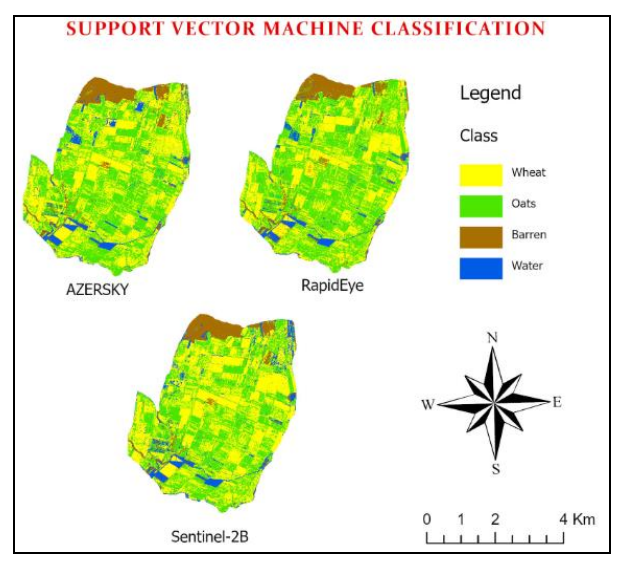

Figure 8. Classified images from various satellites by SVM method

\subsection{Classification accuracy}

An accuracy assessment of a classified land cover data set has been performed using some automated feature extraction protocols. Four cloths high-resolution land cover data set were generated in the form of a raster data set stored inside a file geodatabase. Accuracy assessment figures out how accurate this land cover data set is by comparing it to the source image data set by using the ArcGIS Pro 2.5 accuracy assessment tools.

Accuracy assessment points have been created that have passed visual validation, and confusion matrices were performed for each classified image. The tree basic classification approaches were evaluated with accuracy assessment procedure and visual interpretation of the result images based on ground truth information (Ustuner, 2014).

Overall accuracy and Kappa coefficient for the classified image from AZERSKY shown in table 4.

\begin{tabular}{|l|c|c|c|c|c|}
\hline \multicolumn{7}{|c|}{ Overall Accuracy of AZERSKY Classified Images } \\
\hline Classification & 02.05 .2019 & 15.05 .2019 & 22.05 .2019 & 03.06 .2019 & 23.06 .2019 \\
\hline MLC & $89,06 \%$ & $77,05 \%$ & $80,70 \%$ & $98,41 \%$ & $93,85 \%$ \\
\hline RTC & $92,42 \%$ & $88,71 \%$ & $68,96 \%$ & $93,44 \%$ & $95,31 \%$ \\
\hline SVM & $93,93 \%$ & $95 \%$ & $84,48 \%$ & $95 \%$ & $93,65 \%$ \\
\hline \multicolumn{5}{|c|}{ Kappa coefficient of AZERSKY Classified Images } \\
\hline Classification & 02.05 .2019 & 15.05 .2019 & 22.05 .2019 & 03.06 .2019 & 23.06 .2019 \\
\hline MLC & 0,84 & 0,67 & 0,72 & 0,98 & 0,91 \\
\hline RTC & 0,89 & 0,84 & 0,56 & 0,91 & 0,93 \\
\hline SVM & 0,91 & 0,93 & 0,78 & 0,93 & 0,91 \\
\hline
\end{tabular}

Table 4. Overall accuracy and Kappa coefficients for AZERSKY classified images

For comparative analysis of results taken from AZERSKY, RapidEye, and Sentinel-2B images, overall accuracy, and Kappa coefficients were presented in table 5.

\begin{tabular}{|l|c|c|c|}
\hline \multicolumn{4}{|c|}{$\begin{array}{c}\text { Overall Accuracy and Kappa coefficients of } \\
\text { Classified Images }\end{array}$} \\
\hline Classification & AZERSKY & RapidExe & Sentinel-2B \\
\hline MLC & $93,85 \%$ & $92,19 \%$ & $84,37 \%$ \\
& $(0,91)$ & $(0,89)$ & $(0,78)$ \\
\hline RTC & $95,31 \%$ & $90,62 \%$ & $84,12 \%$ \\
& $(0,93)$ & $(0,86)$ & $(0,77)$ \\
\hline SVM & $93,65 \%$ & $81,25 \%$ & $92,06 \%$ \\
& $(0,91)$ & $(0,73)$ & $(0,88)$ \\
\hline
\end{tabular}

Table 5. Overall accuracy and Kappa coefficients for classified images 
According to accuracy assessment results, for the MLC classified image of June 23, 2019 dated AZERSKY image; overall classification accuracy was $93,85 \%$, kappa value was 0,91 ; for RapidEye image overall classification accuracy was $92,19 \%$ and kappa value was 0,89 , for Sentinel-2B image overall accuracy was $84,37 \%$ and kappa value $-0,78$. For the RTC classification of AZERSKY image; overall classification accuracy was $95,31 \%$, kappa value was 0,93 ; RapidEye image overall classification accuracy was $90,62 \%$ and kappa value was 0,86 , for Sentinel-2B image overall accuracy was $84,12 \%$ and kappa value $-0,77$. For the SVM classification of AZERSKY image; overall classification accuracy was $93,65 \%$, kappa value was 0,91 ; RapidEye image overall classification accuracy was $81,25 \%$ and kappa value was 0,73 , for Sentinel-2B image overall accuracy was $92,06 \%$ and kappa value $-0,88$.

Thereby, the highest accuracy and kappa coefficient was identified for RTC supervised classified image from AZERSKY satellite, 95,31\%, and 0,936 accordingly. But at the same time, for making a final conclusion, the producer and user accuracy should be considered.

\section{CONCLUSION}

The analysis and application of AZERSKY, RapidEye and Sentinel-2B images presented for agricultural monitoring have shown that how remote sensing data from various sources, in combination with other ancillary data, can be successfully used for prompt monitoring and assess the condition and existing status of major crops in a particular selected for research territory.

The kappa coefficient and overall accuracy factors were used to assess the classification accuracy. Assessment of results outlined that all classification procedures come to a sensible precision in crop locations and types identification.

In conclusion, using various satellite images with aim to improve the accuracy of mapping to crop type and area grown in the selected for study area has been determined.

Thus, as a result of the work carried out, the main goal of the study was achieved, the images obtained from various satellites in the optical range were applied, and a simple mechanism for the automated processing of these images using machine learning methods for land cover/land use classification based on the ArcGIS Pro 2.5 software was created.

\section{ACKNOWLEDGEMENTS}

The author would like to thank Mr. Elchin Hasanov from the Sheki Regional Agrochemical Laboratory for providing ground data of the study area.

\section{REFERENCES}

Alganci U., Sertel E., Kaya S., Ustundag B. A research on Agricultural Mapping Capabilities of the SPOT 6 satellite images. 2nd International Conference on Agro-Geoinformatics: Information for Sustainable Agriculture, Agro-Geoinformatics 2013, 93-96

Atzberger, C. Advances in Remote Sensing of Agriculture: Context Description, Existing Operational Monitoring Systems and Major Information Needs. Remote Sens. 2013,5, 949-981. doi.org/10.3390/rs5020949
Brisco, B.; Brown, R.J.; Hirose, T.; McNairn, H.; Staenz, K. Precision agriculture and the role of remote sensing: A review. Can. J. Remote Sens. 2014, 24, 315-327

Candiago, S.; Remondino, F.; De Giglio, M.; Dubbini, M.; Gattelli, M. Evaluating Multispectral Images and Vegetation Indices for Precision Farming Applications from UAV Images. Remote Sens. 2015, 7, 4026-4047, doi:10.5194/isprsarchivesXL-7-195-2014

Enderle, D. and Weih, R.C. 2005. Integrating supervised and unsupervised classification methods to develop a more accurate land-cover classification. Journal of the Arkansas Academy of Science, Vol. 59, 65-73

Erickson J.D. 1984. The LACIE Experiment in Satellite Aided Monitoring of Global Crop production. // The Role of Terrestrial Vegetation in the Global Carbon Cycle: Measurement by Remote Sensing. - SCOPE, 191-217

Esetlili M. T., Filiz B., Sanli F. B., Kaan K., Ustuner M., Cigdem G., Cem G., Yusuf K. Comparison of Object and PixelBased Classifications for Mapping Crops Using Rapideye Imagery: A Case Study of Menemen Plain, Turkey. International Journal of Environment and Geoinformatics, Vol: 5 Issue:2, August 2018, 231-243, doi:10.30897/ijegeo.442002

Kulik K.N., Rulev A.S., Yuferev V.G., Koshelev A.V., Kosheleva O. Yu., Shinkarenko S.S., Tkachenko N.A. Geoinformation monitoring of agroecosystems using remote sensing data. Materials of the All-Russian Scientific Conference (with international participation) "Application of Remote Sensing Measures in Agriculture", St. Petersburg, 2015, 151155

Mikhailenko I.M. Scientific, methodological and algorithmic basis for assessing the productive and sanitary condition of crops according to remote sensing data. Materials of the AllRussian Scientific Conference (with international participation) "Application of Remote Sensing Measures in Agriculture", St. Petersburg, 2015, 37-40

Ormeci C., Alganci U., Sertel E. Identification of Crop Areas Using SPOT - 5 Data Identification of Crop Areas Using SPOT - 5 Data. FIG Congress 2010 Facing the Challenges - Building the Capacity Sydney, Australia, 11-16 April 2010, 2014, 11-16

Tucker, C. J., Holben B.H., Elgin J. H., and McMurtrey J. E. Relationship of spectral data to grain yield variation Photogrammetric Engineering \& Remote Sensing, vol. 46, no.5, May 1980, 657-666

Ustuner, M., Sanli, F. B. Testing the Sensitivity of Vegetation Indices for Crop Type Classification Using Rapideye Imagery. FIG Working Week 2015, Sofia Bulgaria, May 2015

Ustuner, M., Sanli, F. B., Abdikan, S., Esetlili, M. T., Kurucu, Y. Crop type classification using vegetation indices of rapideye imager. The International Archives of the Photogrammetry, Remote Sensing and Spatial Information Sciences, Volume XL7, 2014 ISPRS Technical Commission VII Symposium, 29 September - 2 October 2014, Istanbul, Turkey, 195-198

Wójtowicz M., Wójtowicz A., Piekarczyk J. (2016). Application of remote sensing methods in agriculture. Communications in Biometry and Crop Science 11, 31-50 